\title{
Three Models of Global Climate Governance: From Kyoto to Paris and Beyond
}

\author{
Published in Global Policy, 9(4), 2018
}

This Version: September 2018

\section{David Held and Charles Roger ${ }^{1}$}

Abstract: The Paris Agreement has emerged as one of the world's most important international treaties. Many believe that it offers a new approach to the problem of climate change, can contribute significantly to the goal of reducing emissions, and may hold lessons for how to govern other cross-border issues. As a result, it has been the focus of considerable debate amongst scholars and policymakers. But how precisely does Paris seek to govern global warming and is it likely to work in practice? We address this question by contrasting the Paris "model" of climate governance with earlier ones associated with the Kyoto Protocol and Copenhagen Accord. These models have taken different approaches to the problem of governing climate change, each with attendant advantages and limitations. The Paris model advances upon earlier efforts in certain respects, but also blends elements from earlier models. We then lay out the central axes of the debate that has emerged about the future of the Paris model, and discuss research illuminating how it may operate in practice. The agreement's success will depend on how

\footnotetext{
${ }^{1}$ David Held is Professor of Politics and International Relations at Durham University and Director of the Global Policy Institute; Charles Roger is Assistant Professor at the Institut Barcelona d'Estudis Internacionals. We wish to thank Thomas Hale and Cameron Harrington for their generous comments on an early draft of this paper.
} 
the agreement is implemented, and on how the UNFCCC process interacts with the complementary approaches to climate governance appearing beyond it.

\section{Policy Implications:}

1. A holistic approach is needed in order to understand the Paris Agreement; that is, what is distinctive and important about it can only be grasped within the historical context of climate negotiations and shifts in the central axes of climate policy dialogue.

2. While the Paris Agreement is concluded, the 'rulebook' in which it is to be embedded has yet to be written. It is imperative now to focus on how the transparency mechanisms, compliance mechanisms and the regular global stock take will operate in practice.

3. The development of a dynamic global climate governance "ecosystem," including further elaboration of the UNFCCC process and specification of the role of nonstate actors, from cities to multinational corporations in meeting climate goals, is essential in order for the Paris Agreement to succeed.

4. Civil society groups need to adjust their advocacy and advisory activities towards a focus on the implementation and operationalization processes that are ongoing at the international level. 


\section{Introduction}

The Paris Agreement is the most important international treaty to be reached by the global community in recent years. The problem it seeks to address is arguably the most pressing and difficult issue of our time. Left uncontrolled, climate change will have vast and deeply disruptive implications for humankind across the world. To forestall the worst of these, radical action to lower global emissions is urgently needed (Stern 2009). Yet, to do so, states must resolve an immensely challenging-some say "wicked"-collective action problem (Barrett 2008; Levin et al. 2012). Largely due to the complexities involved, made even more intractable by disagreements over historical injustices and responsibility for global warming, the negotiations under the United Nations Framework Convention on Climate Change (UNFCCC) stagnated for over twenty years (Gupta 2014). In 2015, however, states managed to overcome some of their most important differences, adopting a new mechanism for limiting greenhouse gas (GHG) emissions that was more ambitious than many had expected.

By breaking the cycle of inaction, the Paris Agreement undoubtedly marked a turning point in the climate regime. After years of delay and the apparent breakdown of negotiations at Copenhagen, climate governance has been put on a new footing. It has shifted from a negotiation phase to one focused more squarely on articulating and implementing what states have agreed. However, what makes the Paris Agreement even more notable is the fact that it was negotiated within an international context characterized by "gridlock" and mounting global risks (Hale et al. 2013; Held \& Roger 2013). Climate change is, in fact, only one of many major contemporary cross-border 
issues, including financial crises, nuclear non-proliferation and global pandemics, that seem resistant to political resolution. As a result, some have thought that the Paris treaty and the negotiation process that produced it may hold lessons for those seeking to solve problems in other areas (Hale \& Held 2017). Anne-Marie Slaughter (2015) has been among the most optimistic, going so far as to argue that the Paris Agreement may offer "a model for effective global governance in the twenty-first century."

Given this, it should come as no surprise that the Paris Agreement has captured the attention of scholars and policymakers. Many are now seeking to understand its political, legal, and normative implications. On the one hand, for example, the agreement raises many important social scientific questions concerning its origins, dynamics, and impact. How did states manage to overcome gridlock in the climate regime? What political and economic forces shaped the Paris outcome itself? And how has the agreement subsequently transformed the politics of climate change both domestically (within states) and internationally (between them)? On the other hand, it also raises a range of questions for global policymaking. What are the strengths and potential weaknesses of the Paris approach? How can it best be developed, deepened, and extended to more effectively and fairly reduce the risks associated with climate change? And, finally, what can we learn from the agreement (if anything) that can help us improve policy outcomes elsewhere? Both sets of questions are interrelated and have become the focus of a large research agenda in the social sciences, as well as considerable debate in the public arena. Without doubt, a great deal hangs on the answers we give. 
To fully understand what is at stake, it is important to situate the Paris Agreement within the historical context of climate negotiations, enhance our understanding of the Paris approach itself, and develop an appreciation of the central axes of the policy dialogue going forward. We seek to do this by first outlining the three basic "models" of global climate governance that states have successively embraced since the signing of the UNFCCC at the Rio "Earth Summit" in 1992: the Kyoto Protocol of 1997, the Copenhagen Accord of 2009 and the Paris Agreement of 2015. These can be thought of as distinct "models" in that they have each combined a set of basic elements or "building blocks" into distinct assemblages that are differentiated from one another in politically consequential ways. By mapping these, we lay out their contrasting logics of and cast the key features of the Paris Agreement in sharp relief, helping us to appreciate its uniqueness and various merits or problems. In doing so, though, we do not privilege any particular dimension of a model, as some have done by seeking to characterize the Paris Agreement as primarily "bottom up" or "hybrid" in nature. Each model is, in the end, much more complex and varied. We therefore seek to portray the models in a more comprehensive manner, comparing and contrasting how they approach a range of different issues, from inter alia their basis in international law to their approach to differentiation and the involvement of non-party actors, like cities, NGOs, and multinational corporations. Only with a more textured understanding of the Paris Agreement and its relationship to past approaches can we begin to collectively answer the kinds of crucial questions outlined above. 
Indeed, towards the end of the article, we discuss how this is critical for any careful evaluation of Paris's future. So far, most efforts to assess the Paris model have focused on particular features or elements of it, such as the likely contribution of the agreement's review mechanism for fostering domestic action and international cooperation. Yet, in doing this, they typically neglect other compensatory (or, as the case may be, problematic) elements, which may shift our assessment in subtle but important ways. Moving forward, we argue, research will need to employ a more holistic understanding of the Paris model in order to grasp fully its implications for efforts to address climate change and any broader lessons it may hold for other areas of global governance. Ultimately, while the Paris Agreement may be less unique and promising than some have claimed, it may be more successful than its worst detractors admit. Its success nevertheless remains uncertain going forward, and is likely to depend significantly on how the agreement is implemented in further rounds of UN negotiations, and on how the UNFCCC process interacts with the many complementary approaches to climate governance developing beyond and alongside of it.

\section{Kyoto: The Emergence of a Legalized Regulatory Model}

The climate regime is often regarded as a quintessential example of gridlock (Hale et al. 2013). Yet it is important to recall that the early stages of its development were in fact characterized by relatively rapid progress. Climate change reached the top of the global policymaking agenda in the late 1980s, largely as a result of a growing awareness of environmental issues and the activism of concerned scientists and politicians (Bolin 2007; Schneider 2009). It became the focus of a number of intergovernmental meetings 
in places like Villach, Noordwijk, and Toronto, and was the subject of several UN general assembly resolutions, including Resolution 45/212, which initiated negotiations for a new global agreement in December 1990. After only two years of talks, states convened at the Earth Summit in 1992 and agreed on the terms of the UNFCCC, which established global objectives related to climate change, codified key principles and a number of basic commitments, and provided a platform for future negotiations. The UNFCCC entered into force in 1994, and negotiations for a new agreement that would set in motion emission reductions were launched in Berlin in 1995. The Berlin Mandate established key parameters defining the kind of agreement states would pursue, including its legal form (it would be binding) and the parties it was intended to apply to (namely, wealthier "Annex I" states). A new global deal-the Kyoto Protocol-was struck only two years afterwards. These were significant steps forward.

Kyoto embodied much of the prevailing wisdom about how to govern environmental problems. In this regard, the ozone regime loomed large (Parson 1993; Bodansky 2013). The 1987 Montreal Protocol was, and remains, one of the most successful multilateral environmental agreements, and states consciously sought to replicate its approach. As a result, the design of Kyoto followed its core regulatory logic. An overall GHG reduction target was established (5 percent below 1990 levels during the first commitment period of 2008-2012), individual reduction targets were negotiated, and, once set, parties were legally obligated to meet their commitments. Some flexibility was allowed. Kyoto did not prescribe a particular domestic approach, for instance. States could use a variety of policies and measures to meet their assigned targets. If domestic efforts were insufficient, 
states could also meet their targets by engaging in emissions trading, participating in "Joint Implementation," or buying carbon offsets through Kyoto's Clean Development Mechanisms (CDM), which would fund projects in the developing world. But, one way or another, they were responsible under international law for meeting specific emissions outcomes. Compliance would be strictly monitored, facilitated, and enforced (Brunnee et al. 2012). And, if a party failed to meet its target, they were to be subject to certain punitive consequences, such as a stricter target in any subsequent commitment period.

Several other features of the Kyoto model are noteworthy. First, there was considerable variation in terms of the obligations states took on. The specific targets that the main Kyoto parties adopted ranged from an allowable increase of 10 percent relative to 1990 levels, in the case of Australia, to a reduction of 8 percent, in the case of Germany. However, as per the Berlin Mandate, only a limited number of relatively wealthy countries had such targets. Developing states, reflecting the strict interpretation of the UNFCCC's principle of Common but Differentiate Responsibilities and Respective Capabilities (CBDRRC) that prevailed at the time, were exempt from new commitments - even voluntary ones (Rajamani 2012a). The idea of including voluntary commitments for developing states was raised during the Kyoto negotiations but encountered staunch resistance and was not adopted, largely as a result of concerns about historical injustices and responsibility for global warming-which developing states believed rested with wealthier countries. Second, given the extent to which their importance has subsequently been recognized, it is worth highlighting the relatively limited part that non-state and sub-state actors played at this point in time. While they 
would serve in a small governance capacity as designated operating entities under the CDM, for instance, the authority they possessed was delegated and tightly circumscribed (Green 2013). Any broader, independent contribution that they might make was not recognized. Climate change was, above all, an issue to be solved by governments and international agreement. States - not cities or private actors - assumed the dominant role.

The Kyoto Protocol can be considered the climate regime's first systematic approach to addressing the problem of global warming. It was instantly lauded by many as a first bold step. But it was immediately attacked as well. Critics argued, first, that it would not be complied with (Victor 2001; Barrett 2008). While Kyoto was "legally binding" and did include a novel compliance mechanism, the threat of enforcement was not thought to be credible. While many states may meet their targets (and most did), many believed this would largely be due to factors external to the agreement, not the risk of being punished (Rosen 2015; Shishlov et al. 2016). Ultimately, little stood in the way when a country, like Canada, failed to meet its obligations and simply exited the treaty. Second, critics argued that even if states complied with the terms of the agreement, it would remain ineffective from a broader ecological perspective. The overarching GHG reduction goal was, for one, not informed by any scientific considerations and would do little to reduce global impacts. Equally important was the related fact that the treaty only covered a very small number of states, as noted above. This raised several concerns (Jacoby, Prinn, and Schmalensee 1998). On one side were those focusing on the problem of "leakage," as polluting firms might simply migrate to unregulated states and undermine the environmental integrity of the agreement. On the other, were apprehensions about the 
decision to exclude many states that were quickly becoming major GHG emitters (Held et al. 2013a; Held et al. 2013b). Though it was important for Annex I states to demonstrate leadership, many questioned the meaningfulness and fairness of any agreement that did not have major emerging economies on board.

Largely due to such concerns, the politics surrounding the subsequent ratification and implementation of Kyoto proved to be highly controversial (Harrison \& Sundstrom 2010). Disquiet about leakage and the fairness of excluding key non-Annex I states, like China, India, Brazil and Indonesia, underpinned the United States' (US) decision not to ratify - and even to remove its signature from - the Protocol (Harrison 2010). This, of course, had the effect of amplifying many of the concerns described above for others, since the largest polluter would not be involved in the most important mechanism for mitigating emissions. Developing states, especially, regarded this move as a critical abdication of leadership, compounding the already profound sense of injustice on their part, which had been the main basis for a strict interpretation of the CBDRRC principle in the first place (BBC 2001; Parks \& Roberts 2008). The US decision also opened the door for states, like Russia, to exert pressure on the remaining Kyoto signatories to extract concessions in exchange for ratification of the treaty (Henry \& Sundstrom 2010). The international community was riven. Eventually, nearly eight years after it was first signed, the Kyoto Protocol did come into force. However, it was clear by that point that the first model of global climate governance was in a state of crisis.

Copenhagen: Moving Towards a Voluntary Governance Model 
As Kyoto came into force, the focus of the UNFCCC negotiations was inevitably turning towards what would come next. The starting point was the launch of a first negotiation "track" in Montreal, in 2005, which aimed to determine the modalities for a second Kyoto commitment period, to begin in 2012 when the first would end. This was an important step, but was primarily expected to involve only the current Kyoto parties, not developing states or the US. Thus, another broader negotiating process seemed to be needed. This began with the yearly Conference of the Parties (COP) to the UNFCCC taking place in Bali in 2007. During this meeting, states adopted the Bali Action Plan that launched a second negotiation track to conclude a new agreement that would secure the involvement of these other states. The relationship between the two tracks was repeatedly contested in the years that followed (Dimitrov 2010). Non-Annex I states claimed that their participation depended on the adoption by wealthier parties of a separate commitment to a second Kyoto commitment period. Most Annex I states, by contrast, envisioned a more integrated approach in which all moved forward under the same legal regime. The overall intention, however, was the same: for states to reach a comprehensive "package deal" for the post-2012 period at the fifteenth COP in Copenhagen in 2009.

Kyoto continued to be an influential model during this time. While its limitations were broadly appreciated, the questions that most concerned prominent experts, like Nicholas Stern, revolved around how to negotiate a "more ambitious, more international and much stronger" agreement-a bigger, better Kyoto (Stern 2009, p.5; G8 2007). A smaller cohort began to doubt the wisdom of this model, though, and prior to Copenhagen a 
"schedules-based" or "bottom up" approach gained some traction among some developed and developing states (Rajamani 2009; Victor 2009). ${ }^{2}$ In the end, the regime would move decisively towards the latter position. However, at first, this happened almost as an afterthought in reaction to the faltering of multilateralism. As the meeting in Copenhagen approached, tensions between parties rose. Developed and developing states were at loggerheads over a range of issues, from the overall emissions target and the legal form of the agreement to financial arrangements and the distribution of responsibilities (Dubash 2009; Dimitrov 2010). These disagreements were compounded by broader developments and shifts at the international level, such as the growing power of several emerging economies and the uneven impact of the global financial crisis, which enhanced the likelihood of gridlock (Hale et al. 2013; Hale \& Held 2017). On top of it all, management of the negotiation process itself was badly bungled by the Danish hosts (Meilstrup 2010). All of this meant that by the time negotiators met at the end of 2009, the possibility of finalizing the kind of treaty that many envisioned had all but evaporated. Failure appeared imminent. And, in the final days of talks, heads of state desperately sought to salvage some kind of positive outcome by striking a deal outlining a more minimalist approach to the problem of climate change: the Copenhagen Accord.

The Copenhagen Accord was, at first, widely regarded as a face-saving operation that, as Navroz Dubash said, "only papered over what was an almost complete collapse of negotiations" (Dubash 2009, p.8). It was, initially, not even accepted as an official UNFCCC outcome. Opposition from states like Bolivia, Sudan, and Tuvalu meant that

\footnotetext{
2 In certain respects, the Bali Action Plan also presaged some of these ideas, with its emphasis on "nationally appropriate mitigation actions" for developing states.
} 
the $\mathrm{COP}$ - which operates by consensus - could only agree to "take note" of the agreement leaders had reached (Rajamani 2010). However, it was largely incorporated into and elaborated by the subsequent Cancun Agreements, a set of official COP decisions reached the following year (Rajamani 2011). And, in this somewhat roundabout manner, a new model of climate governance began to take shape-one that turned Kyoto on its head (Bodansky 2013; Andresen 2015). At its heart, Copenhagen initiated a move towards a model of global climate governance that would operate, at bottom, according to strictly voluntary governance logic. States would pledge, of their own accord, the actions they would be willing to take. In some cases, these pledges might represent a meaningful contribution to reducing emissions and were expressed as Kyoto-style quantitative targets that could, in theory, be monitored and verified. In others, they promised little more than "business-as-usual" or were expressed as vaguely stated (and sometimes conditional) promises that would be almost impossible to evaluate. All of these, though, would be taken "as is," and simply recorded in official information documents maintained by the UNFCCC secretariat. They would not be subjected to negotiation and were not designed ex ante to "add up" to meet an overall target, as under Kyoto. Instead, Copenhagen depended almost entirely on the "bottom up" actions of states.

The agreement did, of course, set a long-term target of limiting global temperatures to $2{ }^{\circ} \mathrm{C}$ above pre-industrial levels. This was one of the more positive accomplishments of the Copenhagen Accord. The $2^{\circ} \mathrm{C}$ target was, in principle, a meaningful goal for the world to aspire to, one that was at least nominally informed by scientific analyses (Gao et al. 2017). However, nothing in the agreement really guaranteed that it would be met. It 
was quickly recognized that even if states fully complied with their pledges their collective efforts would still fall well short of what was needed (Rogelj et al. 2010; UNEP 2010). In addition to this, there were to be no real consequences if states failed to make or achieve a pledge. The agreement itself was, for one, "non-binding." It was not an international treaty, like Kyoto, but a political statement of intentions or aspirations. Signatories therefore had no international legal obligations to make pledges or follow through on any of their promises. Further, while certain monitoring, reporting, and verification (MRV) and international consultation and analysis (ICA) mechanisms were called for, these would put little pressure on states to comply. However limited, the kinds of arrangements established by the Kyoto Protocol designed to ensure states fulfilled their obligations were entirely absent.

Despite this - or, more likely, because of it - state participation in the agreement was at least much more extensive than under Kyoto. Copenhagen was, by design, intended to be open to all. And, following its initial troubles, it attracted fairly widespread support. One hundred and fourteen states were listed in the Accord's "chapeau" as having agreed to its terms. Another 37 states later assented, too, bringing the total to 144. Even more importantly, by the end of 2012, 42 Annex I states and 44 non-Annex I states had made voluntary pledges of various kinds. The latter commitments, which were considered quite ambitious (Held et al. 2013a), signaled an important shift in the notion of differentiation that had proved so challenging under Kyoto. Under the Accord, both Annex I and nonAnnex I states were encouraged to make pledges on a relatively even basis, which represented an initial move away from the strict interpretation of the CBDRRC principle 
embedded in the Berlin Mandate and Kyoto. Developing states were adopting increasingly "symmetrical" obligations (Rajamani 2011). Nevertheless, important elements of differentiation remained. Annex I parties were, for instance, expected to put forward quantitative Kyoto-style targets, while developing countries were only expected to pledge "Nationally Appropriate Mitigation Actions," or NAMAs, which did not need to be framed in this way. These commitments would also be recorded in two distinct lists: one for Annex I states and another for non-Annex I states. Another example is related to transparency mechanisms: while one system would cover wealthier states, a separate regime was created for developing ones. And, finally, special mechanisms (such as the Green Climate Fund) were created to finance (to the tune of $\$ 100$ billion per year by 2020) non-Annex I efforts.

Ultimately, most observers remained disappointed by the Copenhagen outcome. Despite positive elements, like the long-term $2^{\circ} \mathrm{C}$ target, widespread participation, and new commitments to finance actions by non-Annex I states, these seemed to be far outweighed by more fundamental problems. State pledges were vague and did not add up, and few mechanisms were in place to ensure that promises would be fulfilled. Nonparty actors, it should also be said, played essentially no role in the new system, despite the fact that they had become much more important within the domain of climate change since the signing of the Kyoto Protocol (Bulkeley et al. 2014). Arguably, as a result, Copenhagen offered merely an "enhanced status quo" (Winkler \& Beaumont 2011, p.640). States (and non-state actors) mainly did what they would be willing to do anyways, within a relatively sparse institutional framework. Despite these flaws, the 
model was nevertheless gradually entrenched in the climate regime. The Cancun Agreements, in particular, developed important elements and provided the approach with a veil of legitimacy by establishing more robust institutional foundations within the UNFCCC process. Eventually, it began to displace the Kyoto model in public debate. Discussions about a subsequent Kyoto commitment period continued after Cancun, but with much less enthusiasm than before. Some of the original signatories, such as Japan and Russia, eventually refused to take part. It was becoming clear, too, that the US and most developing countries would never sign on to any arrangement associated with or even resembling Kyoto. As these facts were established, the global climate policy dialogue shifted. It went from being one that was mainly about strengthening and broadening the Kyoto model to one focused on improving the approach at the heart of the Copenhagen Accord. Out of this, elements of a new model began to take shape.

\section{Paris: Forging a New Approach to Climate Change}

The first major step towards the Paris Agreement was taken at the Seventeenth COP in Durban in 2011. There, states agreed to initiate a "process to develop a protocol, another legal instrument or an agreed outcome with legal force under the Convention applicable to all parties" (UNFCCC 2011). This process was expected to culminate in 2015 with an agreement that would come into force in 2020. Although its phrasing left much room for interpretation, the Durban Platform launched states on a path towards what many hoped would be a legally binding agreement that would, for the first time, apply to all states (Rajamani 2012b). While it still embraced the UNFCCC's CBDRRC principle, it also signaled a collective move towards a system that would embrace even more 
"symmetrical" commitments. Along the way, interestingly, it gave some renewed impetus to the Kyoto model, since agreement on the Durban Platform was secured with a promise by the remaining Kyoto signatories for a second commitment period ending in 2020. But, in fact, this was the final gasp of a "pure" Kyoto-based approach. By the next COP in Warsaw it was clear that commitments under the Protocol would be short-lived and that, while certain elements of the Kyoto model might feature in the post-2020 deal, the thinking of policymakers had shifted decisively towards an approach whose central logic would draw significantly, and perhaps somewhat paradoxically, on Copenhagen. States agreed to develop in advance of Paris their "intended nationally-determined contributions," or INDCs, which were akin to their Copenhagen pledges and would serve as the centerpiece of the agreement they were aiming to reach.

In addition to this emerging consensus on the general outline of a deal, a number of factors coalesced in the years after Durban to help states broker agreement. In this regard, the situation in the lead-up to Paris contrasted sharply with that of Copenhagen. First, many of the key states engaged in assiduous behind-the-scenes diplomacy to ensure they were closely aligned on the most important issues (Brun 2016). In late 2014, for instance, China and the US announced a carefully negotiated bilateral climate accord that outlined their joint ambitions and vision for a future agreement (Goodell 2014). Second, these efforts were complemented by growing evidence of widespread commitment to ambitious action on the part of: a) states, through the growing number of INDCs that were steadily being released in advance of the Paris COP; b) global cities and multinational corporations, who had become prominent "global governors" over the previous 15 years 
through a range of public commitments and initiatives; and, c) concerned citizens and civil society groups, who engaged in enormous demonstrations and intense public lobbying, all of which generated significant political momentum (Bulkeley et al. 2014; Jacobs 2016; Andonova et al. 2017; also see Avant et al. 2010). Finally, it is important to appreciate the skillful steering and management of the negotiation process by the UN Secretary General, the UNFCCC secretariat, and French hosts of the COP (see, for instance, Pasztor 2016). While none of these factors were sufficient on their own, they jointly helped to facilitate a successful conclusion to the negotiations.

The agreement states reached was remarkable not only because it finally broke the impasse that had stymied coherent and systematic action in the climate regime; it was hailed as well, as we noted earlier, because it represented an even higher level of ambition than many thought achievable at the time. Certainly, there are reasons to support this view. Paris combined features from the two earlier approaches in novel ways and, in certain instances, advanced upon them in some important respects; see Figure 1, which presents in schematic form the key elements of the two model we have discussed already and contrasts them with those of Paris. The overarching temperature goal offers an initial a case in point. The Paris Agreement enshrines the $2^{\circ} \mathrm{C}$ target originally established in the Copenhagen Accord. However, it moves beyond it in several ways as well. First, it adds that states will aim to not only meet the $2^{\circ} \mathrm{C}$ target but will attempt to hold temperatures "well below" this target, including an aspirational $1.5^{\circ} \mathrm{C}$ goal. The agreement states, specifically, that parties should "pursue efforts" to limit global temperature rise to $1.5^{\circ} \mathrm{C}$ above pre-industrial levels, partly in recognition of the fact that 
meeting such a target would help to "significantly reduce the impacts and risks of climate change," particularly for small island developing states (UNFCCC 2015, Article 2). Second, the agreement states that the temperature goal is to be met by peeking global emissions as soon as possible, and pursuing major reductions in the years afterwards, in order to achieve "a balance between anthropogenic emissions by sources and removals by sinks of greenhouse gases in the second half of this century" (Ibid, Article 4). Essentially, this articulation of the agreement's purpose amounts to a long-term goal of bending the global emissions trajectory downward to achieve net emissions neutrality.

Figure 1 Comparing the Three Models

\begin{tabular}{|l|l|l|l|}
\hline Model Elements & $\underline{\text { Kyoto }}$ & $\underline{\text { Copenhagen }}$ & $\underline{\text { Paris }}$ \\
\hline Target & $5 \%$ reduction goal & $2^{\circ}$ C global limit & $1.5-2^{\circ} \mathrm{C}$ global limit \\
\hline Legal Nature & Binding & Non-binding & Hybrid \\
\hline Governing Logic & Regulatory & Voluntary & Catalytic \\
\hline State Participation & Narrow & Wide & Near-universal \\
\hline Differentiation & Hard & Medium & Soft \\
\hline Non-Party Actors & Minor role, strictly & Larger role but & Significant role, \\
\hline & delegated by & independent of the & involving UNFCCC \\
& UNFCCC & UNFCCC process & "orchestration" \\
\hline
\end{tabular}

Another way in which the Paris Agreement advances upon earlier efforts is that it embeds such targets within a legally binding agreement. Strictly speaking, the Paris Agreement is 
an international treaty, as defined by the Vienna Convention on the Law of Treaties (Bodansky 2016). It is, therefore, a wholly different kind of instrument than the Copenhagen Accord and Cancun Agreements. Thus, for instance, while the earlier $2{ }^{\circ} \mathrm{C}$ global target they set was entirely precatory in nature - as a matter of international law, at least - it is made mandatory by the Paris Agreement: parties are now collectively legally obligated to meet the new $1.5-2^{\circ} \mathrm{C}$ global goal. However, upon closer inspection, what is particularly interesting is the extent to which the agreement in fact blends binding and non-binding elements, generating a wide spectrum of interlocking commitments (Rajamani 2016b; Bodansky, Brunnee, and Rakamani 2017). To some degree this hybridity is a feature of all international treaties (Aust 2000). A binding international agreement will often place a range of different expectations on parties. Some may be "hard" legal imperatives that states must adhere to in order to be in compliance, while others are comparatively "softer," more voluntary, and more flexible by comparison. This could be said of Kyoto, for instance. In the case of the Paris Agreement, though, legal hybridity has been elevated to a form of art and this feature of the agreement proved critical for establishing the core logic of the governance arrangement it establishes.

At the heart of the Paris Agreement are the nationally determined contributions (NDCs), which are the "pledges" that parties aim to achieve. ${ }^{3}$ These are akin to the voluntary commitments that states made under the Copenhagen Accord in that they are not up for negotiation or designed ex ante to "add up" to meet the overarching collective target. In contrast with Kyoto, pledges are put forward by states and taken "as is." Another

3 After Paris, parties dropped the "intended" component of the epithet. 
similarity stems from the fact that they are not legally binding. The agreement does not obligate parties to meet their pledges, nor does it sanction them if they do not. ${ }^{4}$ Again, this feature sharply differentiates Paris from the Kyoto Protocol, in which states were legally accountable for achieving specific emissions outcomes. At the same time, though, the Paris Agreement moves beyond Copenhagen by setting states' pledges within a legally binding framework that builds around them a range of important procedural obligations. For instance, each party must prepare, communicate and maintain an NDC that reflects their "highest level of ambition" (UNFCCC 2015, Article 4). This ensures that all states, not just a few leaders, make some kind of contribution and are fully invested in the Paris process at all times. The agreement also prescribes that when communicating their NDCs, parties "shall provide the information necessary for clarity, transparency and understanding," and that pledges will be collected in a single public registry maintained by the UNFCCC secretariat, making it easier to track progress. Finally, while it may not be legally "mandatory" to meet the target set out in an NDC, parties are expected to pursue domestic mitigation measures with the "aim" of doing so.

A further way in which the Paris Agreement moves beyond Copenhagen and Kyoto is that it establishes a binding, ongoing and iterative process designed to "catalyze" action over time (Falkner 2016; see Hale 2018 for more on the concept of "catalytic institutions"). While the voluntary Copenhagen pledges only covered the period up to 2020 and the hard Kyoto Protocol targets would only establish obligations for discrete

\footnotetext{
4 The Paris Agreement does establish a compliance mechanism, in name, but the agreement states that it will be "expert based" and operate in a "transparent, nonadversarial and non-punitive" manner, see UNFCCC 2015, Article 15.
} 
commitment periods, the parties to Paris are expected to maintain NDCs at all times, update them in a 5-year cycle, and publish biennial reports tracking emissions, GHG "removals," and progress towards implementation. ${ }^{5}$ Each successive update of an NDC, the agreement states, is expected to "represent a progression beyond the Party's then current nationally determined contribution" (UNFCCC 2015, Article 4). The biennial progress reports are, in turn, subjected to regular technical review, and each party is to take part in a "facilitative, multilateral consideration" regarding implementation of their NDC (Ibid, Article 13). This review process is then expected to feed into and be complemented by a more general "global stocktake," also occurring on a 5-year cycle, which will aim to evaluate "collective progress towards achieving the purpose of [the] Agreement and its long term goals" (Ibid, Article 14). The stocktake will consider a range of different types of information relevant to implementation of the various objectives of the Paris Agreement, especially the long-term $1.5-2^{\circ} \mathrm{C}$ degree temperature goal. Its conclusions are then anticipated to feed back into the next iteration of states' NDCs. The first global stocktake is planned to take place in 2023 , just prior to the first official update of states' NDCs in 2025.

To date, 179 parties have ratified the Paris Agreement, which came into force on 4 November 2016 - a much better and faster outcome than initially expected. A total of 170 parties have also submitted their initial NDCs. This is attributable, in part, to the agreement's legal design, which is both highly structured and flexible where needed,

\footnotetext{
${ }^{5}$ Developed states are also expected to provide information on the finance, technology and capacity building support they provide. Developing states, in turn, are expected to provide information on the finance, technology and capacity building support they receive, or which they require.
} 
setting an ambitious "direction of travel" while reducing sovereignty costs to the greatest extent possible (Bodansky et al. 2017). This has been a winning formula. But part of the reason for this widespread political appeal must also be attributed to the agreement's new approach to differentiation. As a treaty "under the UNFCCC," the Paris Agreement clearly embraces the principle of CBDRRC. Yet it also departs from earlier agreements by offering a significant amendment to this central idea. It does so by typically adding the qualifier "in light of national circumstances" whenever it is used in the text, which suggests a degree of temporal and geographical fluidity and flexibility not present in earlier interpretations of the term. It also employs the idea of differentiation in a number of distinct ways across issues (Rajamani 2016). In certain areas, such as the "core" procedural obligations related to mitigation and transparency, commitments are almost fully symmetrical. This was important for satisfying certain Annex I states, like the US, who repeatedly demanded "balanced" action from their non-Annex I counterparts. In others, it allows for significant levels of differentiation. The content of the non-binding NDCs, for example, is left almost entirely to the discretion of states. Here, "selfdifferentiation" is the rule. This, in turn, was critical for bringing developing states on board and helping to ease the ratification process in the key states-the US, especially. Arguably, the main area where a "traditional" notion of differentiation still prevails is with respect to finance, where more-developed parties are expected to provide finance to less-developed ones. ${ }^{6}$

\footnotetext{
${ }^{6}$ Even here, however, the agreement expands the set of officially recognized contributors or donors by adding that "other states" may be expected to provide finance as well.
} 
One final contrast between the Paris approach and earlier governance models regards the extent to which it embraces non-state and sub-state actors - "non-Party stakeholders" in the Paris parlance. As we noted earlier, the Kyoto Protocol and Copenhagen Accord afforded non-state actors only a minor role, if any. ${ }^{7}$ Over time, however, it was increasingly widely recognized that cities, civil society groups, multinational corporations, and others, had become part of a dynamic "groundswell" of transnational climate governance initiatives (Bulkeley et al. 2014; Roger et al. 2017). In view of this, and especially their potential to "bridge" the ambition gap prior to and beyond 2020, parties adopted a number of decisions aimed at enhancing their efforts (Hale 2016). This was done, initially, in advance of Paris, through the Lima-Paris Action Agenda, which promoted the actions of non-party stakeholders and created the Non-State Actor Zone for Climate Action (NAZCA) platform, which allows these to be registered and promoted at the global level. The decision adopting the Paris Agreement then expanded this initiative in two ways (UNFCCC 2015b). First, parties agree to hold a regular "high-level event" as a platform for parties and non-party stakeholders to network with one another and announce new initiatives. Second, parties decided to appoint two "high-level champions" who would be responsible for engaging with stakeholders on the behalf of the UNFCCC, organizing the high-level event, and facilitating and strengthening, or "orchestrating," voluntary efforts (Hale \& Roger 2014). The first major initiative they spearheaded was the Marrakech Partnership for Global Climate Action, which provides a roadmap for

\footnotetext{
${ }^{7}$ As noted earlier, while transnational climate governance had become an important phenomenon by the time of Copenhagen, this fact went unacknowledged in the agreement itself. The Copenhagen Accord did not establish any relationship between the UNFCCC process and the voluntary initiatives that were appearing outside of it. The UNFCCC Secretariat was, as a result, conspicuously absent as an orchestrator of transnational climate initiatives at the time (Hale \& Roger 2014).
} 
collaboration between governments and other stakeholders during the pre-2020 period, and establishes several new programs designed to initiate, enhance and track transnational action (UNFCCC 2016).

\section{Moving Forward? The Prospects for Global Climate Governance After Paris}

As our review has demonstrated, the Paris Agreement establishes a model of global climate governance that differs in important ways from the two major approaches that have been previously pursued - namely, Kyoto and Copenhagen. In certain respects, like the $1.5-2^{\circ} \mathrm{C}$ goal and the extent of state and non-state participation in the arrangement, it has clearly advanced upon these earlier efforts, surprising many with its level of ambition. In other respects, it offers a novel combination of earlier features. ${ }^{8}$ It marries, for example, the legalized transparency and review mechanisms of Kyoto and the UNFCCC with the non-binding pledges of the Copenhagen Accord. Of course, much remains to be done to elaborate some of its most important components. The Paris "rulebook" has yet to be written. Thus, at present, we still do not know exactly how the transparency mechanisms, compliance mechanisms, and the global stocktake will operate in practice. Future decisions will be required to determine how these will work, and others will surely be needed to strengthen those provisions perceived as, or revealed to be, inadequate. Despite this, the broad contours of the Paris model are clear and a growing debate has emerged over its future prospects. Some argue that, while the agreement may suffer from certain deficits, there are reasons for guarded optimism about

\footnotetext{
${ }^{8}$ In other respects, to be sure, it is worth noting that Paris has not surpassed its predecessors. In the area of finance, for instance, the Paris Agreement largely restates or simply formalizes promises that have been made at earlier points in time.
} 
the new path that it has cut in the global governance landscape. However, others are more pessimistic, arguing that the Paris model is unlikely to put nations on a road towards decarbonisation of the global economy.

Observers of the first type generally argue that the Paris model is more aligned with the underlying nature of the problem of global warming (Slaughter 2015; Höhne et al. 2017; Morgan and Northrop 2017). They acknowledge that the NDCs states have put forward are insufficiently ambitious at present. ${ }^{9}$ They recognize, as well, that states' pledges are non-binding and that there are no official penalties for non-compliance. They point out, in addition, that binding Kyoto-style targets never stopped states from exiting an agreement when these proved difficult to achieve. Enforcement at the international level was never particularly credible. Under these circumstances, then, focusing on facilitating greater ambition and success - not punishing failure - is more likely to galvanize the kind of action that is needed. This, they note, is exactly what Paris is all about. The Paris Agreement sets up a mechanism for "ratcheting up" the ambition of states over time. The pledge-and-review process, in particular, provides states with regular, repeated opportunities to "name and shame" their peers, putting pressure on them to contribute more, and it empowers domestic stakeholders by providing a "hook" with which to hold policymakers to account (Falkner 2016; Keohane \& Oppenheimer 2016). These kinds of indirect channels for influence have-we know from other areas of international politics - often been even more important than legalized global enforcement mechanisms for mobilizing action (Dai 2010). And, perhaps just as importantly, by now engaging in

\footnotetext{
${ }^{9}$ Although studies have offered contrasting estimates of their impact, there is widespread agreement that states' pledges fall short of what is needed. See Höhne et al. 2017.
} 
direct "orchestration" to facilitate non-state and sub-state action, the regime can leverage the efforts of those attempting to induce change in myriad ways (Hale 2018).

To be sure, those expressing optimism about the Paris model are not blind to its faults. They recognize that it is far from perfect. But, given the evident problems associated with previous models, it may be the "only approach that could work," as Anne-Marie Slaughter (2015) has said. Others are not so sure that even this is right, however. More pessimistic observers believe that, even with its legalized pledge-and-review process, the Paris Agreement does not represent the "breakthrough" that many have portrayed it to be. Instead, they say, it is at best an incremental advance upon a model that has already been tried - with meagre results (Allan 2018; Bang et al. 2016; Dauvergne 2018). For the most part, these critics argue, Paris simply repackaged key elements of the Copenhagen Accord and legitimatized the growing emphasis on business and city-led transnational governance schemes. As such, it is likely to suffer from many of the same deficits. Much faith is being placed on the idea that a combination of widened participation, a regular pledge-and-review process and peer pressure will induce a virtuous, upward spiral of ambition. But, equally, it might not: we might also see a vicious circle, as pledges, pressure, and actions repeatedly fall short of what is needed. Both dynamics are logically possible, but, given the lacklustre record of "bottom-up" pledges, pessimists believe that the latter outcome seems more likely. If so, the main impact of the Paris model may be to reinforce a status quo that primarily serves the short-term interests of wealthy elites and powerful, polluting states at the expense of the global environment. 
As these contrasting views suggest, much hinges on whether elements of the Paris model, like the review process, will work as expected. It should come as no surprise, then, that scholars have started to study these dynamics on a smaller scale. Scott Barrett and Astrid Dannenberg, for instance, have attempted to recreate in the laboratory a pledge-andreview process similar to the one that Paris sets up, where players choose a target, make pledges, and contribute to the provision of a collective good (Barrett \& Dannenberg 2016). Their aim was to understand the difference that adding periodic "review" makes. They found that while adding a review process may increase the collective target that gets chosen and the ambition of players' pledges, it has only a small effect on their actual contributions. The initial results were, therefore, not particularly encouraging. However, it should be noted immediately that the scenario they construct abstracts considerably from the real world-and the Paris model itself. It does not take important elements into account, such as the role of lobbying by domestic interest groups, the contribution of transnational initiatives, changing levels of public concern, or transparency or comparability of contributions. Some of these factors could reasonably be expected to improve cooperation. But others may well impede it. Much more work will be needed to understand how such mechanisms can actually alter national policies in practice, as some new research is seeking to do by looking to other regimes (see, for instance, Hale 2017b). In particularly, a more comprehensive understanding of the agreement and its various mechanisms - beyond the review mechanism - is necessary before we can fully evaluate its prospects. The recent work by Barrett and Dannenberg nevertheless offers an initial warning. While it may offer a genuine improvement upon Copenhagen, the "catalytic" 
pledge-and-review process at the core of the Paris model may, on its own. be far from the "paradigm shift" that some optimists have claimed it to be.

\section{Conclusion: Developing a Dynamic Climate Governance Ecosystem}

From the claim that the pledge-and-review process and other individual elements of the Paris Agreement may not offer a panacea or may not work as well as expected, it does not follow that the Paris model itself should be discarded. Politically, a Kyoto-style outcome was (and remains) a non-starter. Even if it was or had been, there are genuine questions as to whether it would have worked. Experience with the Kyoto Protocol, so far, has not been wholly encouraging (Rosen 2015). Although it had some underappreciated elements, another limited "enhanced status quo" agreement, like the Copenhagen Accord, would likely have sent the UNFCCC regime into a dangerous state of crisis. The Paris Agreement-although its success in the global battle against climate change remains an open and potentially problematic question-at least holds some promise for doing so, opening a new door to progress. Its appearance has, crucially, put an end to over twenty years of negotiations and shifted the UNFCCC regime more squarely into an action-oriented, implementation mode. The actual process of implementation may be inadequate and incomplete at present and there may be genuine worries about whether it will work in practice, but a foundation now exists that can, in principle, be built on, improved, and complemented by a range of other initiatives. How these processes and the broader politics of climate change play out in the upcoming years will be decisive for determining its future prospects. 
Precisely how the Paris model will evolve is hard to determine, but, given what we know so far, is its success is likely to depend on the development of a dynamic global climate governance "ecosystem" in which the many interdependent parts of the broader Paris model interact in mutually facilitative ways. The UNFCCC and the Paris Agreement are naturally at the core of this model, providing overarching goals for the world, a broad catalytic framework in which national targets towards those goals can be set and supported, and where progress is periodically reviewed. For this core arrangement to work, important developments will need to take place within the UNFCCC itself. The rules for making pledges, for instance, must be made especially clear and straightforward, making it possible for states to be held to account for their promises, even if this does not occur through a Kyoto-style compliance mechanism. The review process, in turn, must provide accurate information about what states are and are not doing. And, overall, states and non-Party stakeholders must have high levels of confidence in the UNFCCC itself, since the review process, the expert advice generated, and the support that officials provide must feed back into and advance domestic policymaking. All of this must be accomplished through the careful writing of the Paris rulebook, which will elaborate how each mechanism is to operate in practice. It will also require reflective revision of those rules over time as practical experience is gained, and even the creation of new "catalytic" arrangements to support implementation as new needs are identified over time.

However, the operation of this "core" global framework will not only depend on how these rules elaborated; it will rest, also, on a range of complementary actions taken below, alongside and outside of it. It will depend, first of all, on politics within 
governments, where national pledges are made and implemented. Governments must be enticed and compelled to take ambitious action. Domestic political dynamics will therefore be critical. This will, in turn, depend upon the mobilization of particular institutions and constituencies within states, as well as a range of sub-state and non-state actors. Civil society groups, for instance, will need to adjust their advocacy and advisory activities in response to the shift towards implementation that is occurring at the international level. Specifically, they will have to refocus their efforts on promoting and facilitating the making and meeting of ambitious pledges, and leveraging the UNFCCC process to hold politicians to account. Initiatives beyond the UNFCCC, like those being undertaken by businesses and cities, as well as others under the Montreal Protocol, the International Civil Aviation Organization, or the International Maritime Organization, will also play a critical role in helping to break the problem of climate change down into its component parts and advancing the goal of decarbonization in specific areas. International organizations, like the World Bank and other development agencies, can also play a critical part in facilitating the efforts of states and non-party stakeholders by providing much-needed resources and expertise. These kinds actions, we think, are not simply complementary to but a central component of the Paris approach.

In short, to succeed, the UNFCCC must be oriented towards enhancing the actions of state and non-Party stakeholders, whose actions must, in turn, be adapted to work within and implement the new institutional context and commitments that the Paris Agreement has created. The Paris model of climate governance recognizes that these kinds of potentially mutually reinforcing actions will be required to move the global economy 
towards a decarbonized state. And, among non-state actors, important strides have been made as well, helping to facilitate a more dynamic governance ecosystem. The American response to the election of Donald Trump offers an example. Trump represented direct threat to the US commitment to Paris, a threat that he subsequently exercised. At first, the notification to withdraw the US from the Paris Agreement sent shock waves through the global community. Encouragingly, though, these shocks were quickly mitigated, partly via the actions of non-state and sub-state actors in the US who quickly committed to fill the void. A coalition of corporations, cities, states, universities and a diverse set of civil society groups promised to nevertheless work towards meeting the US's Paris commitment. Trump and his supporters may yet undo these important new sources of American commitment to the Paris model. Yet their actions testify to the vitality of the climate governance model that is emerging.

Of course, Trump is not an isolated figure disrupting the pursuit of global cooperation on environmental and other pressing global challenges. A vicious circle of "self-reinforcing gridlock" compounds the problems faced by the global community, adding to the conditions that have spurred the rise of nationalism and the anti-global backlash (Hale \& Held 2017). In many countries across the world, political leaders are now promising that by putting their nation first and ending intrusive international agreements and regimes, they can establish a new era of national greatness. Such forces may, in the future, constitute one of the most significant threats to the success of the Paris model, as well as other areas of international cooperation. But, ultimately, in a world of global enmeshment and interconnectedness, whether through climate change or other global problems, the 
reassertion of national autonomy in this way does not increase control; it weakens it. We must not underestimate the potential consequences. Global challenges threaten to overwhelm human life in the twenty-first century. Acting together to ensure that the Paris model works, along with meeting the challenge of other global risks, is the only viable way of ensuring that humankind continues to flourish in the twenty-first century. It remains the best option we have.

\section{Works Cited}

Allan, J.I., 2018. The Dangerous Incrementalism of the Paris Agreement. Unpublished manuscript.

Andonova, L., Hale, T.N. \& Roger, C., 2017. National Policies and Transnational Governance of Climate Change: Substitutes or Complements? International Studies Quarterly, 61(2), pp.253-268.

Andresen, S., 2015. International Climate Negotiations: Top-down, Bottom-up or a Combination of Both? The International Spectator, 50(1), pp.37-41.

Avant, D., Finnemore, M. \& Sell, S., 2010. Who Governs the Globe? In D. D. Avant, M. Finnemore, \& S. Sell, eds. Who Governs the Globe?. Cambridge: Cambridge University Press.

Bang, G., Hovi, J. \& Skodvin, T., 2016. The Paris Agreement: Short-Term and LongTerm Effectiveness. Politics and Governance, 4(3), pp.209-218.

Barrett, S., 2008. Climate treaties and the imperative of enforcement. Oxford Review of 
Economic Policy, 24(2), pp.239-258.

Barrett, S. \& Dannenberg, A., 2016. An experimental investigation into 'pledge and review' in climate negotiations. Climatic Change, 138(1-2), pp.339-351. Available at: http://dx.doi.org/10.1007/s10584-016-1711-4.

BBC, 2001. Anger at US Climate Retreat. BBC News. Available at: http://news.bbc.co.uk/2/hi/science/nature/1248278.stm.

Bodansky, D., 2013. A Tale of Two Architectures: The Once and Future U.N. Climate Regime. In H.-J. Koch et al., eds. Climate Change and Environmental Hazards Related to Shipping: An International Legal Framework. Boston: Martinus Nijhoff Publishers.

Bodansky, D., Brunnee, J. \& Rakamani, L., 2017. International Climate Change Law, Oxford: Oxford University Press.

Bolin, B., 2007. A History of the Science and Politics of Climate Change: The Role of the Intergovernmental Panel on Climate Change, Cambridge: Cambridge University Press.

Brun, A., 2016. Conference Diplomacy: The Making of the Paris Agreement. Politics and Governance, 4(3), pp.115-123.

Brunnee, J., Doelle, M. \& Rajamani, L., 2012. Promoting Compliance in an Evolving Climate Regime, Cambridge: Cambridge University Press.

Bulkeley, H. et al., 2014. Transnational Climate Change Governance, Cambridge: Cambridge University Press.

Dai, X., 2010. Global regime and national change. Climate Policy, 10(6), pp.622-637. Available at: http://dx.doi.org/10.3763/cpol.2010.0146. 
Dauvergne, P., 2018. The Coming Crisis of Planetary Instability. In C. Hay \& T. Hunt, eds. The Coming Crisis. Cham, Switzerland: Palgrave Macmillan.

Dimitrov, R.S., 2010. Inside UN Climate Change Negotiations: The Copenhagen Conference. Review of Policy Research, 27(6), pp.795-821.

Dubash, N.K., 2009. Copenhagen: Climate of Mistrust. Economic and Political Weekly, $\operatorname{xliv}(52), \mathrm{pp} .8-11$.

Falkner, R., 2016. The Paris Agreement and the new logic of international climate politics. International Affairs, 92(5), pp.1107-1125. Available at: http://dx.doi.org/10.1111/1468-2346.12708.

G8, 2007. Growth and Responsibility in the World Economy: Summit Declaration, Heiligendamm, Germany. Available at: https://www.g8.de/Content/EN/Artikel/_g8-summit/anlagen/2007-06-07-gipfeldokumentwirtschaft-eng,templateId=raw, property=publicationFile.pdf/2007-06-07gipfeldokument-wirtschaft-eng.pdf.

Gao, Y., Gao, X. \& Zhang, X., 2017. The $2{ }^{\circ} \mathrm{C}$ Global Temperature Target and the Evolution of the Long-Term Goal of Addressing Climate Change - From the United Nations Framework Convention on Climate Change to the Paris Agreement. Engineering, 3(2), pp.272-278.

Goodell, J., 2014. The Secret Deal to Save the Planet: Inside the high-stakes drama behind Obama's China climate talks. Rolling Stone.

Green, J.F., 2013. Rethinking Private Authority: Agents and Entrepreneurs in Global Environmental Governance, Princeton: Princeton University Press.

Gupta, J., 2014. The History of Global Climate Governance, Cambridge: Cambridge 
University Press.

Hale, T., 2016. "All Hands on Deck": The Paris Agreement and Nonstate Climate Action. Global Environmental Politics, 16(3).

Hale, T., Held, D. \& Young, K., 2013. Gridlock: Why International Cooperation is Failing When We Need It Most, Cambridge.

Hale, T. \& Roger, C., 2014. Orchestration and transnational climate governance. The Review of International Organizations, 9(1), pp.59-82.

Hale, T.N., 2018. Catalytic Cooperation. Unpublished manuscript.

Hale, T.N., 2017. Under What Conditions Does International Review Alter National Policy? Refining Concepts and Building Theory. Paper presented at the 10th Annual Conference on the Political Economy of International Organizations.

Hale, T.N. \& Held, D., 2017. Beyond Gridlock, Cambridge: Polity Press.

Harrison, K., 2010. The United States as Outlier: Economic and Institutional Challenges to US Climate Policy. In K. Harrison \& L. M. Sundstrom, eds. The Comparative Politics of Climate Change. Cambridge, MA: MIT Press.

Harrison, K. \& Sundstrom, L.M., 2010. Global Commons, Domestic Decisions: The Comparative Politics of Climate Change, Cambridge, MA: MIT Press.

Held, D. \& Roger, C., 2013. Global Governance at Risk, Cambridge: Polity Press.

Held, D., Roger, C. \& Nag, E.-M., 2013a. A Green Revolution: China’s Governance of Energy and Climate Change. In D. Held, C. Roger, \& E.-M. Nag, eds. Climate Governance in the Developing World. Cambridge: Polity Press.

Held, D., Roger, C. \& Nag, E.-M., 2013b. Climate Governance in the Developing World, Cambridge: Polity Press. 
Henry, L. \& Sundstrom, L.M., 2010. Russia and the Kyoto Protocol: From Hot Air to Implementation? In K. Harrison \& L. M. Sundstrom, eds. The Comparative Politics of Climate Change. Cambridge, MA: MIT Press.

Jacobs, M., 2016. High pressure for low emissions How civil society created the Paris climate agreement. Juncture, 22(4), pp.314-323.

Keohane, R.O. \& Oppenheimer, M., 2016. Paris: Beyond the Climate Dead End through Pledge and Review? Politics and Governance, 4(3).

Levin, K. et al., 2012. Overcoming the tragedy of super wicked problems: constraining our future selves to ameliorate global climate change. Policy Sciences, 45(2), pp.123-152. Available at: http://link.springer.com/10.1007/s11077-012-9151-0 [Accessed August 29, 2013].

Meilstrup, P., 2010. The Runaway Summit: The Background Story of the Danish Presidency of COP15, the UN Climate Change Conference. In N. Hvidt \& H. Mouritzen, eds. Danish Foreign Policy Yearbook 2010. Denmark: Danish Institute for International Studies, pp. 113-135.

Parks, B.C. \& Roberts, J.T., 2008. Inequality and the global climate regime: breaking the north-south impasse. Cambridge Review of International Affairs, 21(4), pp.621-648.

Parson, E.A., 1993. Protecting the Ozone Layer. In P. M. Haas, R. O. Keohane, \& M. A. Levy, eds. Institutions for the Earth: Sources of Effective International Environmental Protection. Cambridge, MA: MIT Press.

Pasztor, J., 2016. The Role of United Nations Secretary-General in the Climate Change Process. Global Policy, 7(3), pp.450-457.

Rajamani, L., 2016. Ambition and Differentiation in the 2015 Paris Agreement: 
Interpretive Possibilities and Underlying Politics. International \& Comparative Law Quarterly, 65(April), pp.493-514.

Rajamani, L., 2009. "Cloud" of Climate Negotiations: From Bankok to Copenhagen and Beyond. Economic and Political Weekly, 44(43), pp.11-15.

Rajamani, L., 2011. The Cancun Climate Agreements: Reading the Text, Subtext and Tea Leaves. International \& Comparative Law Quarterly, 60(1), pp.499-519.

Rajamani, L., 2012a. The changing fortunes of differential treatment in the evolution of international environmental law. International Affairs, 88(3), pp.605-623.

Rajamani, L., 2012b. The Durban Platform for Enhanced Action and the Future of the Climate Regime. International \& Comparative Law Quarterly, 61(1), pp.501-518.

Rajamani, L., 2010. The Making and Unmaking of the Copenhagen Accord. International \& Comparative Law Quarterly, 59(3), pp.824-843.

Rogelj, J. et al., 2010. Analysis of the Copenhagen Accord pledges and its global climatic impacts - a snapshot of dissonant ambitions. Environmental Research Letters, 5, pp.1-9.

Roger, C.B., Hale, T.N. \& Andonova, L.B., 2017. The Comparative Politics of Transnational Climate Governance. International Interactions, 43(1), pp.1-25.

Rosen, A.M., 2015. The Wrong Solution at the Right Time: The Failure of the Kyoto Protocol on Climate Change. Politics \& Policy, 43(1), pp.30-58.

Schneider, S., 2009. Science as a Contact Sport: Inside the Battle to Save the Earth's Climate, Washington, DC: National Geographic Society.

Shishlov, I., Morel, R. \& Bellassen, V., 2016. Compliance of the Parties to the Kyoto Protocol in the first commitment period. Climate Policy, 16(6), pp.768-782. 
Slaughter, A.-M., 2015. The Paris Approach to Global Governance. Project Syndicate. Stern, N., 2009. The Global Deal: Climate Change and the Creation of a New Era of Progress and Prosperity, New York: PublicAffairs.

UNEP, 2010. Emissions Gap Report: Are the Copenhagen Accord Pledges Sufficient to Limit Global Warming to $2^{\circ} \mathrm{C}$ or $1.5^{\circ} \mathrm{C}$ ? A Preliminary Assessment, Nairobi.

UNFCCC, 2011. Establishment of an Ad Hoc Working Group on the Durban Platform for Enhanced Action, Available at:

https://unfccc.int/sites/default/files/resource/docs/2011/cop17/eng/09a01.pdf.

UNFCCC, 2016. Marrkech Partnership for Global Climate Action,

UNFCCC, 2015. Paris Agreement, UNFCCC.

Victor, D.G., 2009. Plan B for Copenhagen. Nature, 461(17), pp.342-344.

Victor, D.G., 2001. The Collapse of the Kyoto Protocol and the Struggle to Slow Global Warming, Princeton: Princeton University Press.

Winkler, H. \& Beaumont, J., 2011. Fair and effective multilateralism in the postCopenhagen climate negotiations. Climate Policy, 10(6), pp.638-654. 